\title{
Exceptional Morphology-Preserving Evolution of Formamidinium Lead Triiodide Perovskite Thin Films via Organic-Cation Displacement
}

\author{
Yuanyuan Zhou, ${ }^{\dagger, \#}$ Mengjin Yang, ${ }^{\text {क, }}$ Shuping Pang, ${ }^{\S}$ Kai Zhu, ${ }^{*}$, and Nitin P. Padture*, ${ }^{\dagger}$ \\ ${ }^{\dagger}$ School of Engineering, Brown University, Providence, Rhode Island 02912, United States \\ ${ }^{\ddagger}$ Chemistry and Nanoscience Center, National Renewable Energy Laboratory, Golden, Colorado 80401, United States \\ ${ }^{\S}$ Qingdao Institute of Bioenergy and Bioprocess Technology, Chinese Academy of Sciences, Qingdao 266101, P.R. China
}

Supporting Information

ABSTRACT: Here we demonstrate a radically different chemical route for the creation of $\mathrm{HC}\left(\mathrm{NH}_{2}\right)_{2} \mathrm{PbI}_{3}$ $\left(\mathrm{FAPbI}_{3}\right)$ perovskite thin films. This approach entails a simple exposure of as-synthesized $\mathrm{CH}_{3} \mathrm{NH}_{3} \mathrm{PbI}_{3}\left(\mathrm{MAPbI}_{3}\right)$ perovskite thin films to $\mathrm{HC}(=\mathrm{NH}) \mathrm{NH}_{2}$ (formamidine or FA) gas at $150{ }^{\circ} \mathrm{C}$, which leads to rapid displacement of the $\mathrm{MA}^{+}$cations by $\mathrm{FA}^{+}$cations in the perovskite structure. The resultant $\mathrm{FAPbI}_{3}$ perovskite thin films preserve the microstructural morphology of the original $\mathrm{MAPbI}_{3}$ thin films exceptionally well. Importantly, the myriad processing innovations that have led to the creation of highquality $\mathrm{MAPbI}_{3}$ perovskite thin films are directly adaptable to $\mathrm{FAPbI}_{3}$ through this simple, rapid chemical-conversion route. Accordingly, we show that efficiencies of perovskite solar cells fabricated with $\mathrm{FAPbI}_{3}$ thin films created using this route can reach $\sim 18 \%$.

$\mathrm{T}$ hin films of organic-inorganic halide perovskites have been studied extensively as light-absorbing materials, which are at the heart of perovskite solar cells (PSCs). ${ }^{1-3}$ The unique combination of low-cost processing ${ }^{2,3}$ and high power-conversion efficiencies (PCEs), ${ }^{4}$ rivaling those of conventional Si-based solar cells, holds out great promise for PSCs. While methylammonium lead triiodide $\left(\mathrm{CH}_{3} \mathrm{NH}_{3} \mathrm{PbI}_{3}\right.$ or $\mathrm{MAPbI}_{3}$ ) perovskite, ${ }^{1}$ with a bandgap of $\sim 1.55 \mathrm{eV}$, is the most widely studied, there is growing interest in formamidinium lead triiodide $\left(\mathrm{HC}\left(\mathrm{NH}_{2}\right)_{2} \mathrm{PbI}_{3}\right.$ or $\left.\mathrm{FAPbI}_{3}\right)$ perovskite. ${ }^{5-7}$ This is primarily due to its smaller band gap $(\sim 1.45 \mathrm{eV})^{5}$ and inherently superior thermal stability. ${ }^{6}$ Since the morphology of perovskite thin films plays a central role in the performance of PSCs, unprecedented effort has been devoted to controlling the thin-film uniformity and/or to tailoring the perovskite microstructures, with particular emphasis on $\mathrm{MAPbI}_{3}$ perovskite. ${ }^{2,3}$ However, the development of effective protocols for the morphological engineering of $\mathrm{FAPbI}_{3}$ perovskite thin films, and their microstructural tailoring, is lagging, ${ }^{2}$ which is associated with the following. First, the "ionic radius" of $\mathrm{FA}^{+}$cation $(2.53$ $\AA)$ is larger than that of $\mathrm{MA}^{+}$cation $(2.17 \AA){ }^{8}$ and the symmetries of $\mathrm{FA}^{+}$and $\mathrm{MA}^{+}$cations are quite different, ${ }^{9}$ both of which are expected to affect the growth kinetics of $\mathrm{FAPbI}_{3}$ perovskite. Second, $\mathrm{FAPbI}_{3}$ also crystallizes in a "yellow" nonperovskite polymorph $\left(\delta-\mathrm{FAPbI}_{3}\right)$, often as a byproduct during $\mathrm{FAPbI}_{3}$ perovskite crystallization, which is undesirable. Therefore, manipulating the formation of $\mathrm{FAPbI}_{3}$ perovskite thin film requires stricter control over the synthetic procedures, which is a major hurdle in the path of realizing its full potential in PSCs.

Typically, hybrid perovskite thin films evolve from the reaction between their organic and inorganic halide precursor phases through "one-step" or "two-step" synthetic processes. ${ }^{2,3}$ Myriad innovations in this regard have been reported in the context of the formation of $\mathrm{MAPbI}_{3}$ perovskite thin films with desirable morphologies and microstructural characteristics. ${ }^{1-3}$ Thus, there is an unprecedented opportunity to take advantage of these significant advances, where the $\mathrm{MAPbI}_{3}$ perovskite phase in the thin film is converted directly to $\mathrm{FAPbI}_{3}$ perovskite phase while preserving the desirable morphologies and microstructures of the original thin film. Ion-exchange reaction ${ }^{10}$ of $\mathrm{MAPbI}_{3}+\mathrm{FA}^{+} \leftrightarrow \mathrm{FAPbI}_{3}+\mathrm{MA}^{+}$may be a possible strategy for the phase conversion. However, there are two intrinsic issues with this strategy: (i) ion-exchange reaction is highly reversible, ${ }^{10}$ which makes control of the forward reaction kinetically challenging, and (ii) in order to conduct this reaction at ambient pressure, the protonated formamidine $\left(\mathrm{FA}^{+}\right)$generally requires to be dissolved in an alcohol solvent that also dissolves the perovskite phases, affecting the film morphologies. As a result, the conversion of a smooth $\mathrm{MAPbI}_{3}$ perovskite thin film to $\mathrm{FAPbI}_{3}$ using ion exchange leads to a dramatic change in the film morphology in the final film (see Figure S1 in Supporting Information (SI)). This is consistent with reports on ion-exchange-based perovskite interconversion. $^{11,12}$

These above issues have motivated us to discover a lowreversibility reaction route, without the use of detrimental solvents, for realizing morphology-preserving $\mathrm{MAPbI}_{3} \rightarrow$ $\mathrm{FAPbI}_{3}$ perovskite conversion. Here, we show that the use of the following single-cation displacement reaction, which can be considered as a redox reaction, is a feasible strategy: ${ }^{13}$

$$
\mathrm{MAPbI}_{3}(\mathrm{~s})+\mathrm{FA}(\mathrm{g}) \rightarrow \mathrm{FAPbI}_{3}(\mathrm{~s})+\mathrm{MA}(\mathrm{g})
$$

Reaction 1 is also depicted in the top section of Figure 1, which involves the reduction of $\mathrm{MA}^{+}$into methylamine $\left(\mathrm{CH}_{3} \mathrm{NH}_{2}\right.$ or $\left.\mathrm{MA}\right)$ and the oxidation of formamidine

Received: March 16, 2016

Published: April 18, 2016 


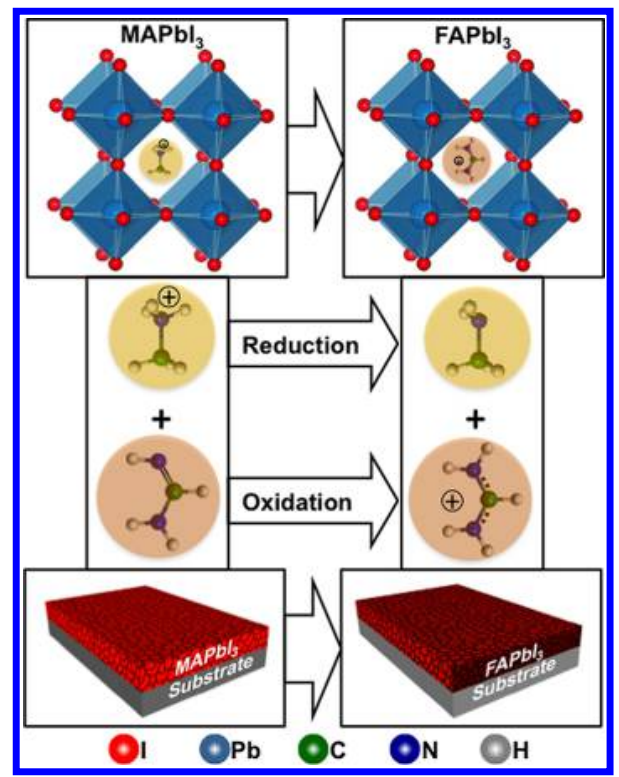

Figure 1. Cation displacement reaction between $\mathrm{MAPbI}_{3}$ perovskite and $\mathrm{HC}(=\mathrm{NH}) \mathrm{NH}_{2}$ (formamidine or FA) gas at $150{ }^{\circ} \mathrm{C}$ resulting in $\mathrm{FAPbI}_{3}$ perovskite and $\mathrm{CH}_{3} \mathrm{NH}_{2}$ (methylamine or $\mathrm{MA}$ ) gas, and schematic illustration depicting morphology-preserving $\mathrm{MAPbI}_{3} \rightarrow$ $\mathrm{FAPbI}_{3}$ perovskite thin-film conversion.

$\left(\mathrm{HC}(=\mathrm{NH}) \mathrm{NH}_{2}\right.$ or $\left.\mathrm{FA}\right)$ into $\mathrm{FA}^{+}$. (For the sake of brevity $\mathrm{MA}^{+}\left(\right.$or $\left.\mathrm{FA}^{+}\right)$is considered as a single cation and MA (or FA) its elementary form.) As shown schematically in Figure 1 (bottom), simply exposing an as-deposited $\mathrm{MAPbI}_{3}$ perovskite thin film to gaseous $\mathrm{FA}\left(150^{\circ} \mathrm{C}, 4 \mathrm{~min}\right)$ completes the rapid $\mathrm{MAPbI}_{3} \rightarrow \mathrm{FAPbI}_{3}$ conversion while retaining the thin-film morphology. The detailed experimental procedures are included in SI. In the experimental setup (Figure S2), the gaseous FA (boiling point $\left.\sim 90^{\circ} \mathrm{C}\right)^{14}$ is produced by reacting formamidine acetate salt with sodium hydroxide at $150{ }^{\circ} \mathrm{C}$ and purified by passing through a $\mathrm{CaO}$ desiccant. The as-produced hot FA gas fills the experimental chamber and then reacts with the predeposited $\mathrm{MAPbI}_{3}$ thin film. Partial or full conversion of $\mathrm{MAPbI}_{3}$ to $\mathrm{FAPbI}_{3}$ is achieved by performing the reaction for specific durations (up to $4 \mathrm{~min}$ ). As expected, the backconversion of the as-converted $\mathrm{FAPbI}_{3}$ thin films to $\mathrm{MAPbI}_{3}$ is very sluggish in MA atmosphere using the similar experimental setup/condition (Figure S3), confirming the limited reversibility of reaction 1 .

To validate the unique "morphology-preservation" feature of the $\mathrm{MAPbI}_{3} \rightarrow \mathrm{FAPbI}_{3}$ perovskite convention process via organic-cation displacement, four different starting $\mathrm{MAPbI}_{3}$ thin films were prepared using four different methods reported in the literature, viz. one-step spin-coating, ${ }^{1,15}$ sequential deposition, ${ }^{16}$ antisolvent treatment, ${ }^{17}$ and MA-gas treatment. ${ }^{18}$ These $\mathrm{MAPbI}_{3}$ films exhibit rather distinct morphologies (Figure 2A,C,E,G) at micro/nanoscales. As reported in the literature, the $\mathrm{MAPbI}_{3}$ perovskite films prepared using one-step spin-coating contains $1 \mathrm{D}$ branch-like structures, ${ }^{15}$ the two-step dipping method results in 3D cuboids, ${ }^{16}$ and the antisolvent/ MA-gas treatments ${ }^{17,18}$ lead to smooth polycrystalline thin films. These morphological characteristics can meet different functional requirements in the devices, which has been demonstrated extensively in the literature. Remarkably, after the organic-cation displacement reaction (reaction 1), the morphologies of the resultant films (Figure 2B,D,F,H) simply mimic those of the original $\mathrm{MAPbI}_{3}$ films in all the cases. A

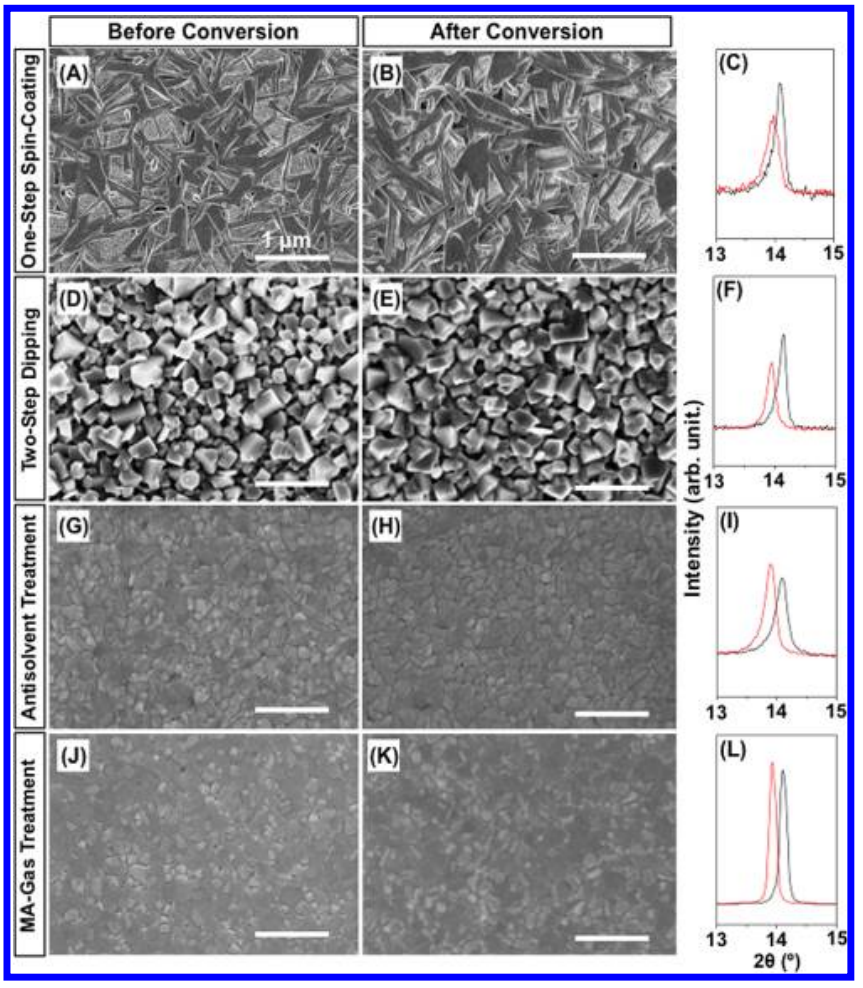

Figure 2. SEM micrographs (top view) of the $\mathrm{MAPbI}_{3}$ perovskite thin films deposited using (A) one-step spin-coating, (D) two-step dipping, (G) antisolvent treatment, and (J) MA-gas treatment. SEM micrographs of the corresponding converted $\mathrm{FAPbI}_{3}$ perovskite thin films (FA gas, $\left.150{ }^{\circ} \mathrm{C}, 5 \mathrm{~min}\right)$ : (B), (E), (H), and (K). Corresponding XRD patterns (black: $\mathrm{MAPbI}_{3}$ (before); red: $\mathrm{FAPbI}_{3}($ after $)$ ): (C), (F), (I), and $(\mathrm{L})$.

closer look at the XRD patterns of these films before and after the conversion reveals that the XRD peaks at $2 \theta \sim 14.1^{\circ}$ for $\mathrm{MAPbI}_{3}$ have shifted to a lower angle of $\sim 13.9^{\circ}$ for $\mathrm{FAPbI}_{3}$ (Figure 2C,F,I,L). Consistent with this observation, the characteristic XRD peaks also shift from $\sim 28.4^{\circ}$ to $28.1^{\circ}$ (Figure S4A-D) in all cases. This confirms the conversion of $\mathrm{MAPbI}_{3}$ to $\mathrm{FAPbI}_{3}$ perovskite. ${ }^{7}$ Note that the small variations in the peak positions between the four cases may be related to the variations in film crystallinity. ${ }^{19}$ Also note that the XRD peak corresponding to the FTO substrate stays the same before and after the conversion (Figure S4), as expected. The success of this FA-gas-induced $\mathrm{MAPbI}_{3} \rightarrow \mathrm{FAPbI}_{3}$ phase conversion, while preserving the thin-film morphology, can be attributed to the following. First, $\mathrm{MAPbI}_{3}$ exhibits cubic crystalline structure (space group $P m \overline{3} m)^{20}$ at elevated temperature $\left(150^{\circ} \mathrm{C}\right.$ ) with a lattice parameter $a=6.31 \mathrm{~nm}$, while $\mathrm{FAPbI}_{3}$ also has a cubic, or a peudocubic, crystal structure (space group $P m \overline{3} m^{21}$ or $P m 31^{20}$ ) with $a=6.36 \mathrm{~nm}$. This inherent structural similarity favors $\mathrm{MAPbI}_{3} \rightarrow \mathrm{FAPbI}_{3}$ conversion. Second, there is a very small difference $(\sim 0.2 \%)$ between the densities of $\mathrm{MAPbI}_{3}$ $\left(4.092 \mathrm{~g} \cdot \mathrm{cm}^{-3}\right)$ and $\mathrm{FAPbI}_{3}\left(4.101 \mathrm{~g} . \mathrm{cm}^{-3}\right),{ }^{20}$ precluding any issues associated with volume change during the $\mathrm{MAPbI}_{3} \rightarrow$ $\mathrm{FAPbI}_{3}$ conversion.

In order to understand the mechanism underlying the conversion process, X-ray diffraction (XRD) patterns are presented in Figure $3 \mathrm{~A}, \mathrm{~B}$ showing the progression of reaction 1 at $t=1-4$ min of FA-gas treatment at $150{ }^{\circ} \mathrm{C}$. A shift of the peaks to lower $2 \theta$ with progressive conversion is observed in Figure 3A. Figure $3 \mathrm{~B}$ shows the details of the XRD patterns in 


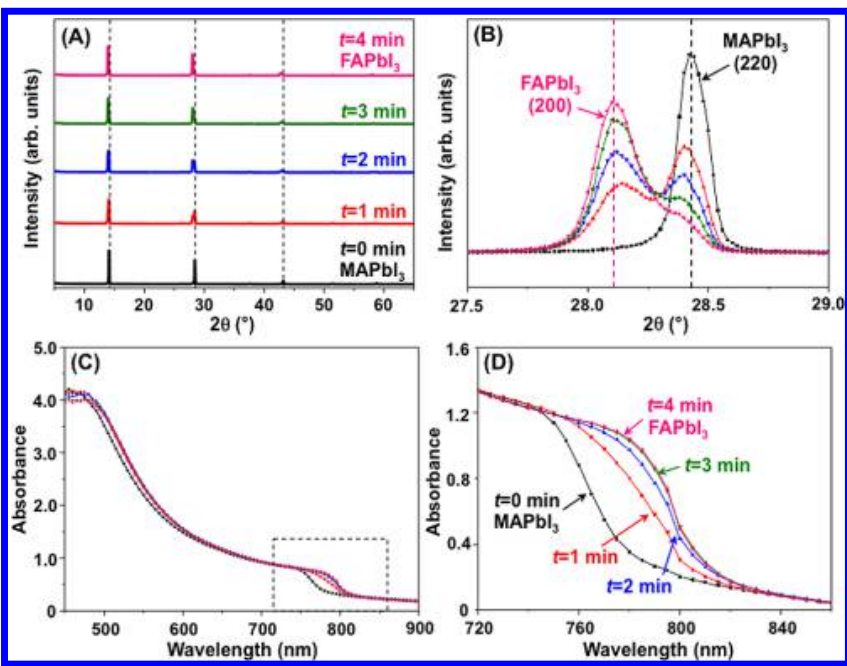

Figure 3. XRD patterns of FA-gas-treated $\left(150^{\circ} \mathrm{C}\right)$ thin films for $t=$ 0-4 min. The dashed lines mark the peak positions of $\mathrm{MAPbI}_{3}$ perovskite. (B) Higher-resolution XRD patterns (overlaid) of thin films corresponding to those in (A). Dashed lines mark the $\mathrm{MAPbI}_{3}$ (220) and $\mathrm{FAPbI}_{3}$ (200) perovskite peak positions, respectively. (C) Optical absorption spectra of the FA-gas-treated $\left(150{ }^{\circ} \mathrm{C}\right)$ thin films for $t=0$ to $4 \mathrm{~min}$. (D) Details of the optical absorption spectra marked by the dashed rectangle in $(C)$.

the $2 \theta$ range $27.50-29.00^{\circ}$. The presence of phase-pure $\mathrm{MAPbI}_{3}$ perovskite at $t=0 \mathrm{~min}$ is confirmed by the presence of the 220 reflection at $2 \theta=28.42^{\circ}$. With exposure to FA gas, the $\mathrm{FAPbI}_{3}$ perovskite 200 reflection starts to appear centered around $2 \theta=28.10^{\circ}$. With increasing FA-gas treatment duration, the intensity of the $\mathrm{FAPbI}_{3}$ perovskite 200 reflection increases, whereas the $\mathrm{MAPbI}_{3} 220$ reflection decreases. At $t=$ $4 \mathrm{~min}$, the $\mathrm{MAPbI}_{3} \rightarrow \mathrm{FAPbI}_{3}$ conversion is nearly complete. It is encouraging that the formation of the undesirable "yellow" nonperovskite $\mathrm{FAPbI}_{3}$ phase and decomposition of perovskite into $\mathrm{PbI}_{2}$ phase are both suppressed during the conversion process, which could be related to the fact that $\mathrm{FAPbI}_{3}$ perovskite phase is thermodynamically more stable at the reaction temperature $\left(150{ }^{\circ} \mathrm{C}\right)$. The overall phase-conversion kinetics are more than an order-of-magnitude faster than the ion-exchange process reported by Eperon et al. ${ }^{12}$ involving the use of solvents. In fact, such rapid conversion kinetics are responsible for the fundamentally different conversion mechanism in our cation-displacement process. In the ion-exchange process, the perovskite conversion progresses by gradual alloying of $\mathrm{FA}^{+}$into $\mathrm{MAPbI}_{3}$, until an equilibrium in the solid-liquid system is reached, with a $\mathrm{FA}^{+}$-rich perovskite alloy $\left(\mathrm{FA}_{x} \mathrm{MA}_{1-x} \mathrm{PbI}_{3}\right)$ as the final product. The sluggish reaction kinetics allows sufficient time for the mixing of the $\mathrm{FA}^{+}$and $\mathrm{MA}^{+}$across the entire film. Correspondingly, the XRD patterns of the partially converted films show symmetric diffraction peaks, indicative of the formation of homogeneous single-phase $\mathrm{FA}_{x} \mathrm{MA}_{1-x} \mathrm{PbI}_{3}$ alloys. ${ }^{12}$ However, in our cation-displacement process, the reaction is much faster, and, thus, a heterogeneous two-phase mixture of $\mathrm{MAPbI}_{3}$ and $\mathrm{FAPbI}_{3}$ is observed in the partially converted perovskite film instead, and the reaction progresses until the $\mathrm{MAPbI}_{3}$ phase is depleted. Figure 3C,D show optical-absorption spectra for the films at $t=0-4 \mathrm{~min}$ of FA-gas treatment at $150{ }^{\circ} \mathrm{C}$, corresponding to the XRD patterns in Figure $3 \mathrm{~A}, \mathrm{~B}$. While the absorbance at low wavelengths in all the thin films is virtually indistinguishable, at longer wavelengths the extension of absorbance into near- infrared (NIR) region is clearly seen in Figure 3C. Figure 3D shows details of the absorption spectra in the NIR range, where the absorption is extended by $\sim 30 \mathrm{~nm}$ into the NIR after conversion. The partially converted films show mixed absorption feature of $\mathrm{MAPbI}_{3}$ and $\mathrm{FAPbI}_{3}$ perovskite thin films. This is consistent with the XRD results in Figure $3 A, B$.

This morphology-preserving $\mathrm{MAPbI}_{3} \rightarrow \mathrm{FAPbI}_{3}$ conversion can find promising application in the fabrication of highefficiency $\mathrm{FAPbI}_{3}$ PSCs. To demonstrate this, a dense, fullcoverage $\mathrm{MAPbI}_{3}$ perovskite thin film was first deposited upon a $250 \mathrm{~nm}$ mesoporous $\mathrm{TiO}_{2} /$ compact- $\mathrm{TiO}_{2} / \mathrm{FTO}$ anode using the MA-gas treatment method described elsewhere, ${ }^{18}$ where the uniform morphology of that thin film is clearly evident in Figure 4A (cross-section). After conversion, the morphology/

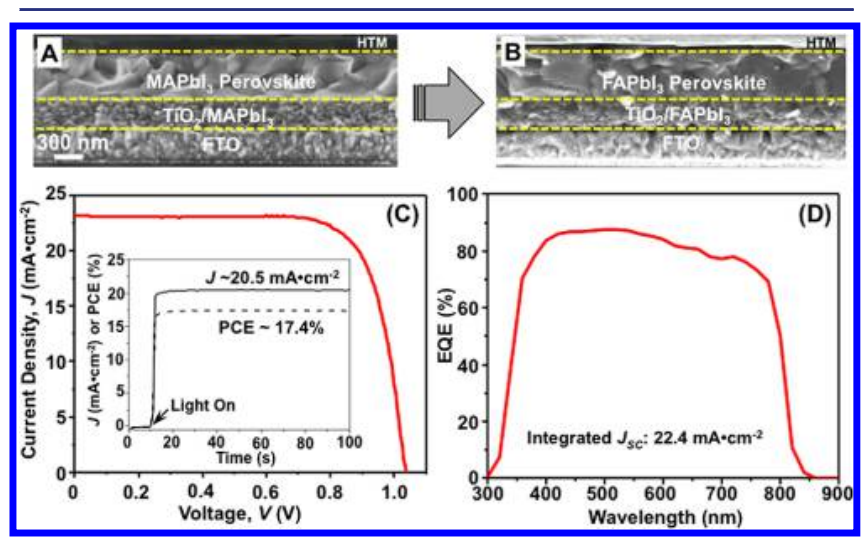

Figure 4. Cross-sectional SEM micrographs: (A) $\mathrm{MAPbI}_{3}$ perovskite thin film and (B) converted $\mathrm{FAPbI}_{3}$ perovskite thin film. (C) $J-V$ response of the best $\mathrm{FAPbI}_{3}$-based PSC (inset: stabilized $J$ and PCE output at maximum power point) and (D) corresponding EQE spectrum.

microstructure of the mesostructured $\mathrm{TiO}_{2} / \mathrm{FAPbI}_{3}$ perovskite and the $\mathrm{FAPbI}_{3}$ perovskite capping-layers appears indistinguishable from the original $\mathrm{MAPbI}_{3}$ thin film (Figure 4B). The morphology preservation is further confirmed by comparing the surface morphologies of the perovskite layers before and after conversion, as shown in Figure S5. The fabrication of the $\mathrm{FAPbI}_{3}$-based PSCs was then completed by depositing Spiro$\mathrm{OMeTAD} / \mathrm{Au}$ cathode. Figure 4A shows the reverse-scan current density-voltage $(J-V)$ response of the best PSC under one-sun illumination, showing PCE of $18.1 \%$ with short circuit current density $\left(J_{\mathrm{SC}}\right)$ of $22.3 \mathrm{~mA} \cdot \mathrm{cm}^{-2}$, open circuit voltage $\left(V_{\mathrm{OC}}\right)$ of $1.04 \mathrm{~V}$, and fill factor $(\mathrm{FF})$ of 0.75 . Since typical $J-V$ hysteresis is observed regardless of the scan rate (Figure S6), the maximum power point current/power output was monitored, showing a stabilized PCE of $17.4 \%$ (inset in Figure 4C). The most impressive performance parameter of the $\mathrm{FAPbI}_{3}$ PSC is the high $J_{\mathrm{SC}}$ of $23.2 \mathrm{~mA} \mathrm{~cm}$, which is consistent with the integrated $J_{\mathrm{SC}}$ of $22.4 \mathrm{~mA} \mathrm{~cm}{ }^{-2}$ obtained from the corresponding external quantum efficiency (EQE) spectrum in Figure 4D. This is clearly due to the extended absorption into the NIR region of the solar spectrum, compared to our previously studied $\mathrm{MAPbI}_{3} \mathrm{PSCs},{ }^{18}$ due to the smaller bandgap of the $\mathrm{FAPbI}_{3}$. Also, excellent reproducibility of the cation-displacement approach is evinced by the PSC performance parameters statistics in Table S1. Furthermore, using a planar polycrystalline $\mathrm{MAPbI}_{3}$ thin film (via the antisolvent treatment method) as the starting film, the $\mathrm{FAPbI}_{3}$ perovskite thin film from this cation-displacement conversion 
process yields a PCE of $\sim 17 \%$ with a high $J_{\mathrm{SC}}$ of $22.2 \mathrm{~mA} \mathrm{~cm}{ }^{-2}$ (Figure S7), which attests to the versatility of this method. These results show that the high quality of the starting $\mathrm{MAPbI}_{3}$ perovskite thin films can be preserved in the resultant $\mathrm{FAPbI}_{3}$ perovskite thin films during the FA-gas-induced conversion, which leads to the high performance in the $\mathrm{FAPbI}_{3}$-perovskitebased PSCs.

In closing, the unprecedented organic-cation displacement approach presented here is very attractive for the processing of high-performance $\mathrm{FAPbI}_{3}$-based PSCs and other types of devices, as it combines synergistically the clear advantage of high-quality $\mathrm{MAPbI}_{3}$ perovskite thin-films deposition protocols and the desirable attributes of the $\mathrm{FAPbI}_{3}$ perovskite. This approach has generic appeal, and it could be extended to the synthesis of other compounds (e.g., $\mathrm{FASnI}_{3}$ ).

\section{ASSOCIATED CONTENT}

\section{S Supporting Information}

The Supporting Information is available free of charge on the ACS Publications website at DOI: 10.1021/jacs.6b02787.

Experimental details and data (PDF)

\section{AUTHOR INFORMATION}

\section{Corresponding Authors}

*kai.zhu@nrel.gov

*nitin padture@brown.edu

\section{Author Contributions}

"These authors contributed equally.

\section{Notes}

The authors declare no competing financial interest.

\section{ACKNOWLEDGMENTS}

Y.Z. and N.P.P acknowledge the support from the National Science Foundation (DMR-1305913, OIA-1538893) for the work performed at Brown University and at NREL. M.Y. and K.Z. acknowledge the support from the Department of Energy SunShot Initiative under the Next Generation Photovoltaics 3 program (DE-FOA-0000990) for the work performed at NREL (DE-AC36-08-GO28308). S.P. thanks the Youth Innovation Promotion Association of CAS (2015167) for additional financial support.

\section{REFERENCES}

(1) (a) Kim, H.-S.; Lee, C.-R.; Im, J.-H.; Lee, K.-B.; Moehl, T.; Marchioro, A.; Moon, S.-J.; Humphrey-Baker, R.; Yum, J.-H.; Moser, J. E.; Grätzel, M.; Park, N.-G. Sci. Rep. 2012, 2, 591. (b) Liu, M.; Johnston, M. B.; Snaith, H. I. Nature 2013, 501, 395. (c) Grätzel, M. Nat. Mater. 2014, 13, 838.

(2) Zhou, Y.; Game, O. S.; Pang, S.; Padture, N. P. L. Phys. Chem. Lett. 2015, 6, 4827.

(3) Zhao, Y.; Zhu, K. I. Phys. Chem. Lett. 2014, 5, 4175.

(4) Best Research-Cell Efficiencies, www.nrel.gov/ncpv/images/ efficiency_chart.jpg (accessed April 17, 2016).

(5) (a) Koh, T. M.; Fu, K.; Fang, Y.; Chen, S.; Sum, T. C.; Mathews, N.; Mhaisalkar, S. G.; Boix, P. P.; Baikie, T. I. Phvs. Chem. C 2014, 118, 16458. (b) Pang, S.; Hu, H.; Zhang, J.; Lv, S.; Yu, Y.; Wei, F.; Qin, T.; Xu, H.; Liu, Z.; Cui, G. Chem. Mater. 2014, 26, 1485. (c) Lee, J.-W.; Seol, D.-J.; Cho, A.-N.; Park, N.-G. Adv. Mater. 2014, 26, 4991.

(6) Eperon, G. E.; Stranks, S. D.; Menelaou, C.; Johnston, M. B.; Herz, L. M.; Snaith, H. I. Energv Environ. Sci. 2014, 7, 982.

(7) (a) Jeon, N. J.; Noh, J. H.; Yang, W. S.; Kim, Y. C.; Ryu, S.; Seo, J.; Seok, S. I. Nature 2015, 517, 476. (b) Yang, W. S.; Noh, J. H.; Jeon, N. J.; Kim, Y. C.; Ryu, S.; Deo, J.; Seok, S. I. Science 2015, 348, 1234. (c) Lv, S.; Pang, S.; Zhou, Y.; Padture, N. P.; Hu, H.; Wang, L.; Zhou, X.; Zhu, H.; Zhang, L.; Huang, C.; Cui, G. Phvs. Chem. Chem. Phvs. 2014, 16, 19206. (d) Wang, Z.; Zhou, Y.; Pang, S.; Xiao, Z.; Zhang, J.; Chai, W.; Xu, H.; Liu, Z.; Padture, N. P.; Cui, G. Chem. Mater. 2015, 27, 7149.

(8) (a) Kieslich, G.; Sun, S.; Cheetham, A. K. Chem. Sci. 2015, 6, 3430. (b) Zhou, Y.; Yang, M.; Kwun, J.; Game, O. S.; Zhao, Y.; Pang, S.; Padture, N. P.; Zhu, K. Nanoscale 2016, 8, 6265.

(9) Mitzi, D. B. In Progress in Inorganic Chemistry; Karlin, K. D., Ed.; John Wiley \& Sons: New York, 1999; Vol. 48, p 1-122.

(10) Harland, C. E. Ion exchange: Theory and Practice; The Royal Society of Chemistry: Cambridge, 1994.

(11) Pellet, N.; Teuscher, J.; Maier, J.; Grätzel, M. Chem. Mater. 2015, 27, 2181.

(12) Eperon, G. E.; Beck, C. E.; Snaith, H. I. Mater. Horiz. 2016, 3, 63.

(13) Silberberg, M. Chemistry, the Molecular Nature of Matter and Change, 4th ed. McGraw Hill, New York, 2006.

(14) ChemSpider Database by Royal Society of Chemistry, www. chemspider.com/Chemical-Structure.61362.html (accessed April 17, 2016).

(15) Hu, Q.; Wu, H.; Sun, J.; Yan, D.; Gao, Y.; Yang, J. Nanoscale 2016, 8, 5350.

(16) Burschka, J.; Pellet, N.; Moon, S.-J.; Humphrey-Baker, R.; Gao, P.; Nazeeruddin, M. K.; Grätzel, M. Nature 2013, 499, 316. Im, J.-H.; Jang, I.-H.; Pellet, N.; Grätzel, M.; Park, N.-G. Nat. Nanotechnol. 2014, 9, 927.

(17) (a) Jeon, N. J.; Noh, J. H.; Kim, Y. C.; Yang, W. S.; Ryu, S.; Seok, S. I. Nat. Mater. 2014, 13, 897. (b) Zhou, Y.; Yang, M.; Wu, W.; Vasiliev, A. L.; Zhu, K.; Padture, N. P. I. Mater. Chem. A 2015, 3, 8178. (c) Yang, M.; Zhou, Y.; Zeng, Y.; Jiang, C. J.; Padture, N. P.; Zhu, K. Adv. Mater. 2015, 27, 6363.

(18) (a) Zhou, Z.; Wang, Z.; Zhou, Y.; Pang, S.; Wang, D.; Xu, H.; Liu, Z.; Padture, N. P.; Cui, G. Anoew. Chem. Int. Ed. 2015, 54, 9705. (b) Pang, S.; Zhou, Y.; Wang, Z.; Yang, M.; Krause, A. R.; Zhou, Z.; Zhu, K.; Padture, N. P.; Cui, G. L. Am. Chem. Soc. 2016, 138, 750.

(19) Zhou, Y.; Vasiliev, A. L.; Wu, W.; Yang, M.; Pang, S.; Zhu, K.; Padture, N. P. I. Phvs. Chem. Lett. 2015, 6, 2292.

(20) Stoumpos, C. C.; Malliakas, C. D.; Kanatzidis, M. G. Inorg. Chem. 2013, 52, 9019.

(21) Weller, M. T.; Weber, O. J.; Frost, J. M.; Walsh, A. I. Phvs. Chem. Lett. 2015, 6, 3209. 